\title{
A disponibilização de fósforo nas águas pelo uso de detergentes em pó: aspectos ambientais e de Saúde Pública
}

\author{
Phosphorus delivered to surface waters resulting from the use \\ of powder detergents: environmental and public health aspects
}

Claudia Maria Gomes Quevedo ${ }^{1}$

Wanderley Silva Paganini ${ }^{1}$

${ }^{1}$ Faculdade de Saúde

Pública, Universidade de

São Paulo. Av. Dr. Arnaldo

715, Cerqueira César.

01246-000 São Paulo SP

Brasil.claugomes@usp.br

\begin{abstract}
This article addresses the social and environmental aspects related to the presence of phosphorus in surface water bodies, assessing the impacts caused by the utilization of powder detergents on the quality and availability of water resources, with particular respect to the occurrence of eutrophication. Based on data concerning the composition and consumption of the products currently sold in Brazil, the evolution of this phenomenon leading to the current situation is reported. Indications are that Brazilian detergents have a low phosphorus content, thus it is possible to infer that these products offer a small risk of impacting the trophic levels of surface waters. There is, however, a need to adjust the content of legislation to market practices, as well as improve public policies related to environmental education. By means of an intensive process of communication and education, awareness about the issue can be raised, keeping this major source of phosphorus in the environment under control and contributing to the increase in the availability of water, through the prevention of eutrophication processes.
\end{abstract}

Key words Water resources, Eutrophication, Phosphorus, Detergents, Public health
Resumo Este artigo aborda a interface social e ambiental da presença de fósforo nas águas de abastecimento, dimensionando os impactos ocasionados pelo uso de detergentes fosfatados em pó sobre a qualidade e a disponibilidade dos recursos hídricos, no tocante à ocorrência da eutrofização. Com base em dados a respeito da formulação $e$ consumo dos produtos comercializados no Brasil, relata a evolução do assunto e apresenta o retrato da situação atual. Indica que os detergentes brasileiros possuem, hoje, baixa concentração de fósforo, de forma que representam um reduzido risco de impacto sobre o nível trófico das águas. Pontua, entretanto, a necessidade de ajustar o conteúdo da legislação à prática do mercado e de aprimorar as políticas públicas relacionadas com a educação ambiental. Mediante um processo efetivo de comunicação e educação, será possível conscientizar a população acerca do assunto, contribuindo para a manutenção do controle dessa importante fonte de fósforo no meio ambiente e para o aumento da disponibilidade hídrica, por meio da prevenção dos processos de eutrofização.

Palavras-chave Recursos hídricos, Eutrofização, Fósforo, Detergentes, Saúde pública 


\section{Introdução}

No início da década de 1960, a indústria de produtos de higiene e limpeza, até então focada na eficiência e na eficácia, passou a ser impelida a incorporar a preocupação ambiental às questões técnicas previstas em seus processos fabris.

Tal mudança de postura foi impulsionada pelos eventos de formação de espuma em rios e reservatórios, com a constatação da sua relação com a ausência de biodegradabilidade dos agentes tensoativos até então utilizados nos detergentes, os alquilbenzenossulfonados de cadeia linear, ou LAS. Foi motivada também, pelo agravamento dos problemas de deterioração da qualidade das águas decorrentes da proliferação de algas e outros organismos aquáticos em eventos de eutrofização, com a identificação da contribuição do tripolifosfato de sódio, ou STPP, utilizado nas formulações dos detergentes em pó para limpeza de tecidos.

Nesse cenário, diversos países passaram a discutir as interações entre uso de detergentes, saúde e meio ambiente, avaliando os reflexos sobre a disponibilidade hídrica e os impactos sobre a qualidade das águas. Na Suíça, em 1962, foi criada a Comission on Detergents, com o objetivo de debater os impactos dos produtos e avaliar sua contribuição para a deterioração dos recursos hídricos. Nos Estados Unidos e Canadá, a organização binacional International Joint Commission (IJC) indicou em seu relatório datado de 1969, a necessidade de regulamentação do uso de fósforo nos detergentes em pó como uma das medidas destinadas à gestão de ambientes eutrofizados ${ }^{1,2}$.

Buscou-se, então, implementar uma lógica para controle do aporte de fósforo nas águas, envolvendo um conjunto de medidas voltadas para o controle das atividades agrícolas e urbanas. Também, passaram a ser impostas regras para fabricação e comercialização de detergentes fosfatados em países como Japão, Estados Unidos, Canadá, Itália, Suíça, Holanda e Alemanha, dentre outros, incluindo o Brasil2.

Por meio do presente trabalho, busca-se retratar o atual cenário brasileiro relativo à utilização do fósforo nos detergentes em pó destinados à limpeza de tecidos, e demonstrar sua evolução. Apresenta a conjuntura social e regulatória acerca do assunto e dimensiona o possível impacto dos produtos atualmente comercializados no país sobre a qualidade das águas, abordando as implicações sobre a disponibilidade hídrica e os reflexos sobre o abastecimento e a saúde pública.

\section{Detergentes fosfatados: do avanço tecnológico à problemática socioambiental}

O desenvolvimento dos detergentes sintéticos, no início do século XX, é considerado um marco evolutivo para o setor de fabricação de produtos para limpeza doméstica, e a comercialização do detergente fosfatado em pó para lavagem de roupas, iniciada em meados da década de 1940, é um fato apontado como o agente transformador do mercado.

Nos detergentes, o fósforo tem a função de builder. Condiciona o sistema e controla a interferência de agentes externos que podem reduzir a eficiência do produto, como temperatura e dureza das águas, conceito este que corresponde à presença de sais, tais como cálcio e magnésio. Considera-se a utilização de fosfato, o fator que propiciou a popularização do uso de detergentes em pó, de forma que, no final da década de 1950, cerca de 10 anos após o início da sua comercialização, o volume de vendas já havia superado o dos sabões convencionais no mercado norte-americano e em diversos países da Europa ${ }^{3}$.

A concentração do builder nos detergentes em pó pode ultrapassar $50 \%$ do peso do produto $^{2,3}$. Assim, dependendo do consumo característico de cada região, pode-se inferir que uma considerável parcela do elemento que é lançada nas águas através dos sistemas de esgotos sanitários, seja proveniente desta fonte. Ou seja, na medida em que os resíduos oriundos da lavagem de tecidos são encaminhados para as redes coletoras de esgotos, podem tornar-se uma importante fonte de fósforo nos ambientes aquáticos.

Nas águas, a presença em excesso de fósforo tende a aumentar a produtividade biológica, podendo desencadear o fenômeno denominado eutrofização. Nesse cenário, pode haver uma drástica redução da disponibilidade hídrica, com diminuição da sua qualidade e quantidade, e crescente perda da capacidade de sustentabilidade do sistema ${ }^{4,5}$. Consequentemente, alguns usos da água podem ficar comprometidos, em especial o abastecimento público, contribuindo para um cenário de escassez.

A título de ilustração, a Figura 1 permite visualizar um bloom de algas registrado em 1972 no Lago Erie, situado na região dos Grandes Lagos, entre os Estados Unidos e o Canadá, e em 2012, na Represa Billings, em São Paulo. A distância geográfica e o extenso intervalo de tempo existente entre esses dois eventos, permite constatar a recorrência do fenômeno. 

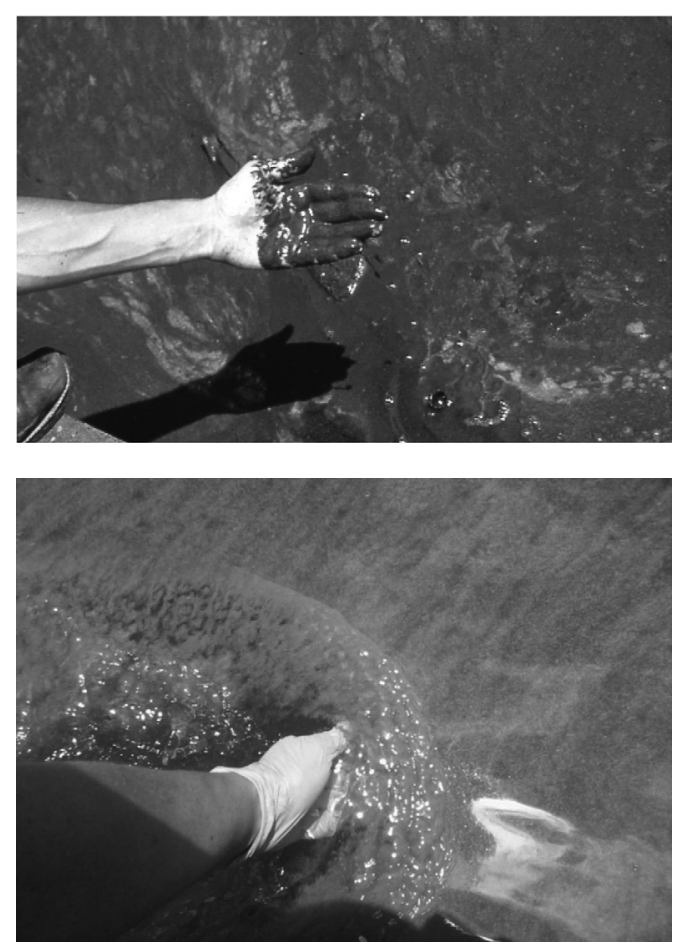

Figura 1. Bloom de algas no Lago Erie - Estados Unidos/Canadá (1972), e na Represa Billings - São Paulo, Brasil (2012).

Fonte: Hartig et al. ${ }^{4}$, Lamparelli et al. ${ }^{5}$.

De forma concomitante, o crescimento não controlado de algas e outros organismos aquáticos pode afetar a saúde humana devido ao potencial incremento da toxicidade. Relatos da Organização Mundial de Saúde (OMS) indicam a relação da presença de organismos tóxicos nas águas com casos de irritação da pele e lacerações no fígado, sistema nervoso e rins. Foi a presença de toxinas provenientes da floração de Microcystis sp em reservatório de Caruaru, no estado brasileiro de Pernambuco, por exemplo, que provocou a morte de dezenas de pacientes em uma clínica de hemodiálise, no ano de 1996. Em mananciais da costa leste dos Estados Unidos, surtos de Pfiesteria piscicida ocorridos na década de 1990, em eventos de eutrofização, provocaram danos neurológicos irreversíveis nas pessoas expostas ao material tóxico e volátil produzido ${ }^{6}$.

Além do potencial efeito deletério de algumas toxinas, casos de contaminação também são relatados devido à aplicação de produtos químicos no tratamento das águas provenientes de mananciais eutrofizados. Na Austrália, em uma ilha localizada na costa nordeste, a aplicação de sulfato de cobre para controle de sabor e odor da água devido à presença da cianobactéria Cylindrospermopsis raciborskii, na década de 1980, determinou a ocorrência de hepato-enterite severa em 140 crianças e 10 adultos. Também, o possível aumento na concentração de nitrato pode desencadear nas crianças a deficiência no transporte de oxigênio pelas células, caracterizando a "Síndrome do Bebê Azul"'.

Paralelamente aos impactos decorrentes da deterioração dos recursos hídricos, a questão do ritmo de exploração das reservas de fósforo no meio ambiente tornou-se também objeto de preocupação e estudo. Dados a respeito da demanda por fósforo em processos industriais e volume das reservas naturais, subsidiaram discussões a respeito da perspectiva de escassez desse elemento, com elaboração de projeções que indicam o possível esgotamento das fontes conhecidas e exploráveis num período de 80 a $100 \mathrm{anos}^{7}$. Os impactos desse cenário são considerados alarmantes, já que o fósforo é um nutriente indispensável e imprescindível para os processos biológicos dos organismos vivos.

A substituição do fósforo nos detergentes, assim, ganha maior amplitude, tornando-se multidisciplinar. À questão da saúde pública e do controle da poluição das águas, são agregadas discussões sobre as técnicas para reciclagem do nutriente, as quais passaram a ser incorporadas por setores como mineração e saneamento ${ }^{7}$. Neste último, um número crescente de experiências volta-se para recuperação do nutriente nos sistemas de tratamento de esgotos, como pela precipitação de estruvita ou pela utilização agrícola.

\section{O paradoxo entre produção, consumo e sustentabilidade ambiental}

Não obstante diversos estudos apontem para a importância da substituição do fósforo nos detergentes, parte dos fabricantes defende a sua manutenção. O principal argumento utilizado é o desempenho do produto, pois ainda que diversos compostos possam ser utilizados como builders em detergentes, defende-se que nenhum deles é capaz de substituir, sozinho, o STPP na mesma condição de eficiência e custo. Outro argumento utilizado em favor da manutenção do uso do fósforo nos detergentes, é a sua alta capacidade de biodegradabilidade e ausência de toxicidade, enquanto alguns de seus substitutos possuem interações ambientais ainda pouco investigadas, como o ácido policarboxílico (PCA) e o ácido nitrilo- 
triacético (NTA), por exemplo ${ }^{2}$. Destacam que a substituição do fósforo por materiais alternativos é bastante complexa, em função da necessidade de manutenção das mesmas condições de custo e eficiência do produto ao consumidor final.

Diversos pesquisadores defendem ainda, que no tocante à eutrofização, somente a implantação dos denominados sistemas terciários ou avançados para tratamento de esgotos seria suficiente para reduzir o aporte de fósforo nas águas. Argumenta-se que tais sistemas poderiam, por si só, remover o fósforo presente nos esgotos de maneira eficiente, tornando desnecessária a redução da parcela proveniente dos detergentes. Por meio desta lógica, entretanto, tende-se a relegar para um segundo plano as medidas preventivas de controle do aporte de fósforo nas águas, bem como, as possibilidades de sua reutilização e reciclagem, a despeito das inúmeras previsões em relação ao esgotamento das suas reservas naturais.

Neste ponto, Xavier et al. ${ }^{8}$ destacam que as medidas preventivas são mais desejadas na questão do controle do aporte de fósforo nas águas devido à maior eficácia e ao menor custo. Tais medidas devem ser acompanhadas do controle das fontes no âmbito da bacia de drenagem, considerando-se que o maior objetivo de qualquer programa de controle e prevenção da eutrofização é a redução da entrada de nutrientes.

Deve-se observar, portanto, que a plena substituição do fósforo nos detergentes envolve questões econômicas, mercadológicas e sociais importantes, além de incertezas relacionadas com a utilização de elementos químicos, cujas interações ambientais ainda estão sendo estudadas. Esse contexto paradoxal, entretanto, não pode impedir a evolução no desenvolvimento de produtos e tecnologias que permitam substituir o fósforo nos detergentes, minimizando os riscos de efeitos deletérios desse produto de limpeza no meio ambiente.

Sob a ótica da sustentabilidade, a regulamentação do uso de detergentes fosfatados ultrapassa a fronteira meramente técnica ou econômica, tornando-se uma questão a ser abordada, cada vez mais, no âmbito das políticas públicas. Como apontam Sorrentino et al. ${ }^{9}$, a política, ao ser entendida no significado estrito do termo, como limite, deve propor a regulação das responsabilidades individuais e coletivas, de maneira interligada pelas circunstâncias sociais e ambientais, com vistas ao alcance do bem comum. Cabe à política pública agregar os saberes técnico e ambiental, transformando-os em valores éticos e de convívio social, de forma a motivar a busca de formas concretas de atuação frente aos problemas, com vistas à manutenção da qualidade de vida das atuais e das futuras gerações.

\section{Panorama mundial e tendências do uso de fósforo nos detergentes}

Como resultado das discussões e estudos desenvolvidos ao longo dos anos, diversos países baniram ou restringiram a utilização de fosfato nos detergentes. Nos Estados Unidos e Canadá, a redução gradual da presença de fósforo nos detergentes foi instituída no início da década de 1970, devido às ocorrências de eutrofização na região dos Grandes Lagos. Em 1998, cerca de 25 Estados norte-americanos haviam abstido do uso de fosfato nesses produtos. No Japão, o uso de detergentes fosfatados foi banido em áreas próximas aos lagos ainda na década de 1980, o que aumentou a pressão social e legal sobre o setor industrial; atualmente, em substituição ao STPP, utiliza-se uma combinação de zeólitas, PCAs e carbonato de sódio. Dados publicados no ano de 2005 indicam que em países do sul da Ásia os builders coexistiam; no norte da Ásia, América Latina, África, o STPP era considerado o componente usualmente utilizado nos detergentes ${ }^{2,3}$.

$\mathrm{Na}$ Figura 2 pode ser visualizado o panorama global resumido da utilização dos diferentes builders em detergentes para limpeza de tecidos, conforme dados relativos ao ano de 2005.

$\mathrm{Na}$ Comunidade Europeia, o nível de aplicação de fósforo nos detergentes para roupa era bastante variável nos Estados-Membros até o ano de 2006, em função das diferenças nos graus de dureza da água e das restrições legais de cada localidade. Enquanto na Suíça, por exemplo, o uso de fosfato foi proibido por lei em 1986, na Polônia, onde não havia legislação ou acordos voluntários regulamentando o assunto, somente cerca de $15 \%$ dos produtos disponíveis no mercado eram livres de STPP. No total, os detergentes sem fósforo correspondiam a cerca de $65 \%$ da disponibilidade do mercado na Comunidade Europeia. Tais dados e os resultados obtidos nos locais onde esses produtos haviam sido banidos, subsidiaram a decisão, colocada em vigor a partir de 30/06/13, de limitar em $0,5 \%$ de fósforo, em peso, para todos os detergentes para limpeza de tecidos comercializados na região abrangida pelos Estados-Membros ${ }^{10}$.

Outro ponto a ser observado, refere-se à inclusão do critério de ausência de fosfato nos mecanismos de rotulagem ambiental para produtos de limpeza e em processos de certificação 


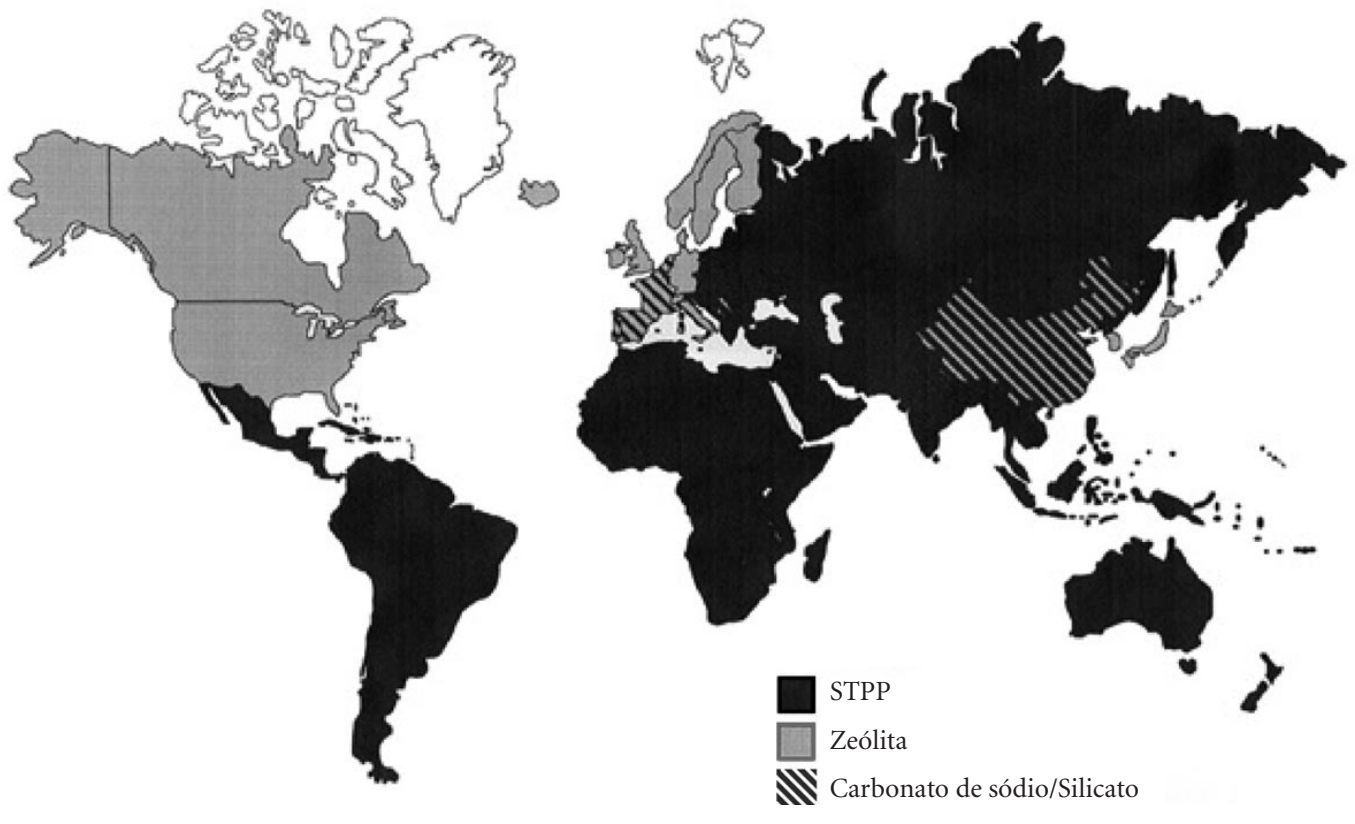

Figura 2. Panorama mundial dos builders utilizados em detergentes destinados à limpeza de roupas nos diferentes países, em 2005.

Fonte: Hauthal ${ }^{3}$.

em sistemas de gestão ambiental dos fabricantes. Dentre estes, pode-se citar o Nordic White Swan, utilizado na Suécia, Finlândia, Dinamarca, Islândia e Noruega e o Blue Eco Angel, da Alemanha. Ademais, esse tópico foi incluído nas diretrizes para rotulagem ambiental dos detergentes comercializados no âmbito da União Europeia, na forma de Eco-label ${ }^{2}$.

\section{Métodos}

Este trabalho foi desenvolvido a partir de uma pesquisa descritiva e exploratória, com abordagem quantitativa aplicada. Tem como base o levantamento e revisão bibliográfica de conceitos teóricos a respeito da presença de fósforo nos detergentes em pó para limpeza de tecidos, e de suas implicações sobre o meio ambiente e a saúde pública, abordando a evolução desse assunto ao longo do tempo.

Utiliza dados estudados por Quevedo ${ }^{11}$, relativos ao consumo e à composição dos produtos atualmente comercializados no Brasil, e ao cálculo de sua contribuição para a disponibilização de fósforo nos esgotos. Para desenvolvimento, são apresentadas informações sobre o estado da arte da condução da regulamentação dos detergentes fosfatados em pó destinados à limpeza de tecidos no Brasil, sobre o setor produtivo, bem como, sobre o nível de consumo do produto pela população. Para tanto, foram consultados os dados publicados nos anuários da Associação Brasileira de Produtos de Limpeza e Afins (ABIPLA) ${ }^{12,13}$.

Para avaliar a contribuição dos detergentes para a presença de fósforo nas águas, e dimensionar os possíveis impactos, foram discutidos dados de Quevedo e Paganini ${ }^{14}$, relativos à formulação dos produtos comercializados no país e à contribuição per capita de fósforo lançada em estações de tratamento do estado de São Paulo. Visa permitir, assim, uma aplicação prática das informações levantadas, subsidiando as discussões a respeito da interface social e ambiental do uso doméstico desse produto.

Também, são apresentadas informações coletadas a respeito da abordagem mercadológica seguida pelo setor produtivo brasileiro e o embasamento dado ao assunto pela legislação em vigor, sob a ótica da prática de comunicação e conscientização dos consumidores a respeito da composição dos produtos comercializados. 


\section{Resultados}

\section{Fósforo nos detergentes em pó no Brasil: estado da arte}

O marco da regulamentação da presença de fosfatos nos detergentes em pó comercializados no Brasil remonta ao ano de 1978 , quando o Ministério da Saúde, através da Agência Nacional de Vigilância Sanitária (Anvisa), instituiu a Resolução Normativa no 01 e impôs o limite máximo de $15 \%$ para a presença de fosfato $\left(\mathrm{P}_{2} \mathrm{O}_{5}\right)$ nesses produtos, em peso. Seguindo as medidas implementadas por outros países, no ano de 2005, o conteúdo dessa norma foi revisado, e por meio da Resolução no 359, do Conselho Nacional do Meio Ambiente (Conama), foi estipulada a redução progressiva dos limites, ao longo de três anos subsequentes, até atingir o valor de 10,99\% de $\mathrm{P}_{2} \mathrm{O}_{5}$ e $4,8 \%$ de fósforo total (P), em peso. Deve-se ressaltar que tais limites são aplicáveis somente aos produtos em pó destinados à limpeza de tecidos ${ }^{11}$.

Atendendo ao estabelecido no Art. 7 da Resolução, foi criado em 2008, ao final do prazo previsto para as reduções graduais estipuladas, um Grupo de Trabalho para analisar os resultados decorrentes das medidas adotadas ${ }^{15}$. Não foi inserida no escopo desse Grupo, a análise das concentrações de fósforo nos produtos comercializados no país, uma vez que, de acordo com o entendimento suscitado, tais informações seriam controladas pelo Instituto Brasileiro de Meio Ambiente e dos Recursos Naturais (IBAMA).

Para tanto, o IBAMA disponibilizou em sua página na internet, um sistema de auto declaração, com o objetivo de permitir que o fabricante ou importador declare anualmente os dados de fósforo utilizados nas diferentes formulações de detergentes em pó e as respectivas produções. Os resultados, no entanto, podem ser acessados somente pelos usuários cadastrados pelo IBAMA, sendo a consulta efetuada diretamente através do sítio do Instituto mediante validação de senha.

Com base nesse banco de dados do IBAMA, o Grupo de Trabalho designado pelo Conama para acompanhamento do assunto, apresentou no ano de 2010 o documento denominado "Relatório Final”, que apontou para o atendimento aos limites estipulados, pelo setor produtivo, e calculou uma redução do aporte de fósforo ao meio ambiente da ordem de $21,5 \%$ no período compreendido entre 2005 e 2008, alterando o aporte desse nutriente nas águas de 40,5 para 31,8 ton/dia ${ }^{15}$. Concluiu, no entanto, pela necessidade da adoção de limites mais restritivos, conforme segue:
“Tendo em vista os novos cenários de fabricação de detergentes em pó no Brasil e o mercado de STPP (que hoje é 100\% importado), bem como os níveis médios atuais adotados na formulação dos detergentes em pó [...] recomenda-se uma revisão da Resolução com limites mais restritivos ${ }^{15 "}$.

\section{Paradigmas de produção/consumo e efeitos ao meio ambiente}

Com relação ao mercado do STPP no Brasil, a análise do período de 22 anos, compreendido entre 1998 e 2010, permite notar uma tendência de mudança no padrão de utilização da matéria-prima por parte da indústria de detergentes do país, que apresentou uma redução de mais de $300 \%$ do volume consumido. Tal situação que fica evidenciada pela verificação da expansão do mercado entre 1998 e 2008, comparativamente ao expressivo declínio apresentado no ano de 2010, quando as reduções estipuladas pelo Conama já se encontravam em vigor. No ano de 1998, calculou-se que das 65.649 toneladas de STPP produzidas, 96\% foram destinadas à indústria de detergente. Em 2008, o consumo brasileiro da matéria-prima havia atingido 81 mil toneladas, dos quais, 95\% haviam sido destinadas aos detergentes. Em 2009, o volume comercializado foi de 75 mil toneladas e, em 2010, de 35 mil toneladas, dos quais, 50\% destinou-se à indústria de detergentes $^{12,16}$.

O detergente em pó para roupas foi apontado, no ano de 2012, como "destaque de popularidade nos lares brasileiros"12. Estava posicionado na liderança de volume de vendas entre as categorias de produtos de limpeza, com 99,1\% de penetração nos lares. Com relação ao consumo per capita médio, o volume comercializado no Brasil foi, na época, estipulado na faixa de $5 \mathrm{~kg} / \mathrm{hab}$.ano, ou 13,7 g/hab.dia.

Já nos dados publicados pela ABIPLA ${ }^{13}$, no ano de 2015, verificou-se um crescimento de $11 \%$ no volume de vendas de detergentes para roupas, comparativamente a 2012. Pode-se estimar, portanto, que o volume comercializado do produto no país tenha passado para $5,6 \mathrm{~kg} / \mathrm{hab}$. ano, ou 15,3 g/hab.dia.

Ainda que os dados publicados pela Abipla, no ano de 2012, indiquem o STPP como builder, sistematicamente empregado nos detergentes comercializados no território brasileiro, na publicação de 2015, a instituição deixou de fazer menção a esse assunto. Pesquisas desenvolvidas em anos anteriores já indicavam uma tendência de mu- 
dança, numa situação condizente com a redução observada no volume de STPP consumido pelos fabricantes de produtos de limpeza no país, conforme abordado anteriormente neste trabalho.

Silva et al. ${ }^{17}$ constataram em pesquisa desenvolvida no ano de 2010, que a concentração de fósforo em quatro amostras de produtos situouse entre $0,87 \%$ e $3,57 \%$ em peso.

No mesmo ano, Souza et al. ${ }^{18}$, analisaram a amostra de um detergente comercializado no país e constataram um teor de fósforo da ordem de $0,21 \%$ em peso. Relataram que a maioria dos produtores haviam se adequado às reduções estipuladas pela legislação.

Em publicação efetuada no ano de 2016, Quevedo e Paganini ${ }^{14}$ relatam que as análises laboratoriais efetuadas em 30 amostras de detergentes em pó comercializados em diferentes regiões do país, indicaram um teor bastante baixo de fósforo. $\mathrm{O}$ valor máximo observado nos produtos analisados foi de $0,01 \%$ em peso, por formulação, resultado sensivelmente inferior ao limite estabelecido pela legislação brasileira que regulamenta o assunto, que é de $4,8 \%$ em peso, porém alinhado com os resultados obtidos nas pesquisas anteriores, conforme citado.

Os resultados dos produtos nacionais podem ser considerados bastante similares ao valor encontrado na análise de amostra de detergente em pó para roupas adquirida no mercado norte-americano, cujo teor de fósforo foi de $0,001 \%$, em peso $^{11}$.

Os valores obtidos para as 30 amostras detergentes brasileiros analisados nessa pesquisa, bem como, o limite para concentração de fósforo atualmente estipulado pela legislação brasileira e o resultado obtido em amostra oriunda do mercado norte-americano, podem ser visualizadas na Tabela 1, a seguir. Cumpre ressaltar que foram estipulados códigos de identificação e controle, visando, desta forma, não expor as marcas e seus respectivos fabricantes.

Por meio desses dados, pode-se verificar que há uma linearidade na composição dos detergentes comercializados no país, não havendo diferenças na concentração de STPP nos produtos conforme a região de comercialização. A fim de auxiliar na visualização dessa constatação, a Figura 3 aponta os Estados onde foram coletadas amostras de detergentes e respectivas concentrações de fósforo, em \% do peso do produto.

Esses resultados ratificam o relato de Trajano $^{19}$, que indica que, no Brasil, os fabricantes optaram por substituir os fosfatos presentes nas formulações de detergentes em pó de forma pau-
Tabela 1. Concentrações mínima, média e máxima de fósforo nos produtos analisados, limite estipulado pela Resolução Conama 359/05 e resultado de amostra de produto norte-americano, em $\% \mathrm{P}$, em peso.

\begin{tabular}{|c|c|c|c|}
\hline Detergente & $\mathbf{P}(\%)$ & Detergente & $\mathbf{P}(\%)$ \\
\hline DET 01 & 0,003 & DET 16 & 0,005 \\
\hline DET 02 & 0,006 & DET 17 & 0,005 \\
\hline DET 03 & 0,005 & DET 18 & 0,004 \\
\hline DET 04 & 0,003 & DET 19 & 0,008 \\
\hline DET 05 & 0,003 & DET 20 & 0,007 \\
\hline DET 06 & 0,004 & DET 21 & 0,008 \\
\hline DET 07 & 0,003 & DET 22 & 0,002 \\
\hline DET 08 & 0,002 & DET 23 & 0,001 \\
\hline DET 09 & 0,003 & DET 24 & 0,002 \\
\hline DET 10 & 0,010 & DET 25 & 0,002 \\
\hline DET 11 & 0,003 & DET 26 & 0,004 \\
\hline DET 12 & 0,005 & DET 27 & 0,003 \\
\hline DET 13 & 0,005 & DET 28 & 0,004 \\
\hline DET 14 & 0,005 & DET 29 & 0,004 \\
\hline DET 15 & 0,005 & DET 30 & 0,005 \\
\hline \multicolumn{2}{|c|}{ P mínimo (\% peso) } & 0,001 & \\
\hline \multicolumn{2}{|c|}{ P médio (\% peso) } & 0,004 & \\
\hline \multicolumn{2}{|c|}{ P máximo (\% peso) } & 0,010 & \\
\hline \multicolumn{2}{|c|}{ Limite Conama 359/05 (\% peso) } & 4,80 & \\
\hline \multicolumn{2}{|c|}{ Produto norte-americano (\% peso) } & 0,001 & \\
\hline
\end{tabular}

Fonte: Quevedo ${ }^{16}$, Quevedo e Paganini ${ }^{19}$.

tada pela sustentabilidade ecológica e pela competitividade econômica.

Ainda que os detergentes fabricados e comercializados no país sejam, hoje, compostos por baixos teores de fósforo, a grande maioria das marcas não faz referências sobre o tema nos rótulos dos produtos. Observa-se que somente alguns fabricantes passaram a adotar rotulagem indicando a ausência de fósforo nas formulações. Deve-se salientar que essa informação sobre a ausência de fósforo nos detergentes não é uma exigência do órgão que fiscaliza o assunto no Brasil, no caso a Anvisa, a despeito do assunto estar na pauta de ambientalistas de diversas localidades do mundo. Uma vez que não há qualquer normativa sobre o assunto, pode-se inferir que tal informação é inserida voluntariamente.

Ademais, como inexistem orientações a respeito da fundamentação ambiental dessa medida, pode-se considerar sua divulgação como eminentemente comercial. Visa diferenciar a marca, sem promover a atuação conscientemente e responsável dos consumidores frente à problemática da disponibilização de fósforo nas águas. $\mathrm{Na}$ Figura 4, pode-se observar imagens re- 


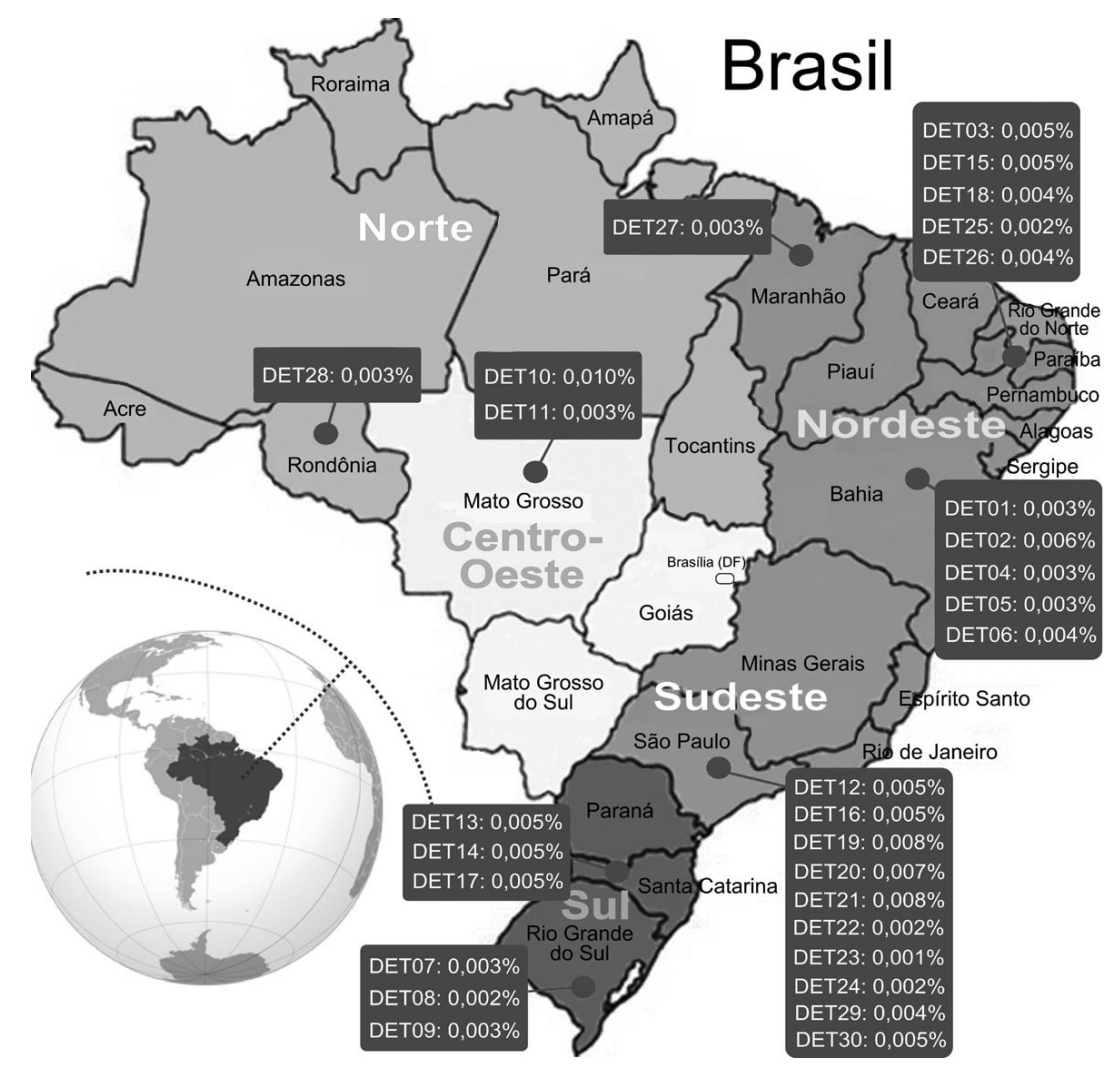

Figura 3. Concentração de fósforo nos produtos analisados (\% peso) e local de aquisição.

Fonte: Quevedo e Paganini ${ }^{14}$.

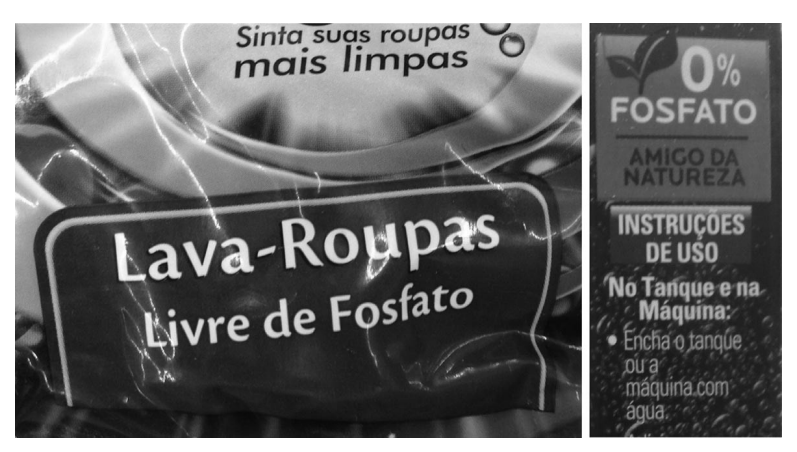

Figura 4. Embalagens de detergentes no Brasil: registro de ausência de fosfato. Agosto/15.

centemente registradas num ponto de venda comercial, de embalagens fazendo referências à ausência de fosfato nos produtos.

Não obstante, deve-se observar que esse movimento, ainda que lento e sem o necessário embasamento legal, pode ser considerado o prenúncio da inserção de novos paradigmas de produção e consumo, no tocante à gestão do uso do fósforo e de seus efeitos sobre o meio ambiente. Mediante o apropriado direcionamento e de forma embasada tecnicamente, por meio de mecanismos regulatórios e de educação ambiental, tais iniciativas poderão ser ampliadas, auxiliando na promoção da sustentabilidade ambiental por meio do controle social

\section{O cenário atual: impactos sobre a qualidade das águas e a disponibilidade hídrica}

Considerando os dados citados sobre consumo per capita médio do produto, estimado hoje em 15,3 g/hab.dia, e a concentração máxima de fósforo nos detergentes, de $0,01 \%$ em peso, a contribuição per capita de fósforo lançada nos esgotos sanitários por meio do uso doméstico de detergentes situa-se, hoje, em cerca de 0,0015 g/hab. dia. Se levado em conta que a faixa de contribuição de fósforo para os esgotos sanitários seja de $0,87 \mathrm{~g} / \mathrm{hab} \mathrm{dia}^{11}$, em média, a participação percen- 
tual dos detergentes frente ao total de fósforo nos esgotos pode ser atualmente calculada, em média, em $0,17 \%$. Este valor, face ao aporte total de fósforo, é considerado muito pouco representativo.

Entretanto, caso estivesse sendo atendido o limite estabelecido pela Resolução Conama $n^{\circ}$ $359 / 05$, que é de 4,8\% de fósforo, em peso, as cargas do nutriente proveniente dos detergentes seriam aumentadas em cerca de 0,73 g/hab.dia. Assim, na hipótese de os limites estabelecidos pela legislação serem efetivamente praticados pelo setor produtivo, o aporte de fósforo nos esgotos por meio dessa fonte seria ampliado, e em muito, de forma que a contribuição de fósforo para os esgotos sanitários passaria de 0,87 para 1,60 g/hab.dia. Nesse cenário, a contribuição dos detergentes passaria de $0,17 \%$ para $46 \%$ do total presente nos esgotos sanitários. Na Tabela 2, po- de-se visualizar o comparativo entre a estimativa de aporte de fósforo nos esgotos com base na atual prática de mercado, e a ampliação hipotética decorrente de uma possível mudança no setor de fabricação de detergentes, com retomada do uso de STPP nos produtos para roupas no limite máximo estabelecido pela Resolução Conama.

Diante desses resultados, pode-se inferir que, caso sejam atendidos os limites legais atualmente vigentes no país para a presença de fosfato nos detergentes em pó destinados à limpeza de tecidos, ocorra uma considerável ampliação do aporte de fósforo nas águas, com implicações sobre a saúde e os recursos hídricos, especialmente sobre as águas de abastecimento. No Gráfico 1, observa-se graficamente esse comparativo, onde se pode visualizar o potencial aumento no aporte de fósforo nos esgotos e, consequentemente, nas

Tabela 2. Fósforo nos esgotos - Comparativo entre a contribuição estimada dos detergentes com base na atual prática de mercado e no limite estipulados pela legislação.

\begin{tabular}{lrc}
\hline & $\begin{array}{r}\text { Situação } \\
\text { Atual }\end{array}$ & $\begin{array}{c}\text { Limite legislação } \\
\text { (Conama 359/05) }\end{array}$ \\
\hline Consumo de detergentes (g/hab.dia) & 15,3 & 15,3 \\
Concentração máxima de fósforo nos detergentes (\%P em peso) & 0,01 & 4,8 \\
Contribuição dos detergentes para o fósforo nos esgotos (g/hab.dia) & 0,0015 & 0,73 \\
Contribuição per capita média de fósforo nos esgotos (g/hab.dia) & 0,87 & 1,60 \\
Participação dos detergentes com relação ao fósforo nos esgotos (\%) & $0,17 \%$ & $46 \%$ \\
\hline
\end{tabular}

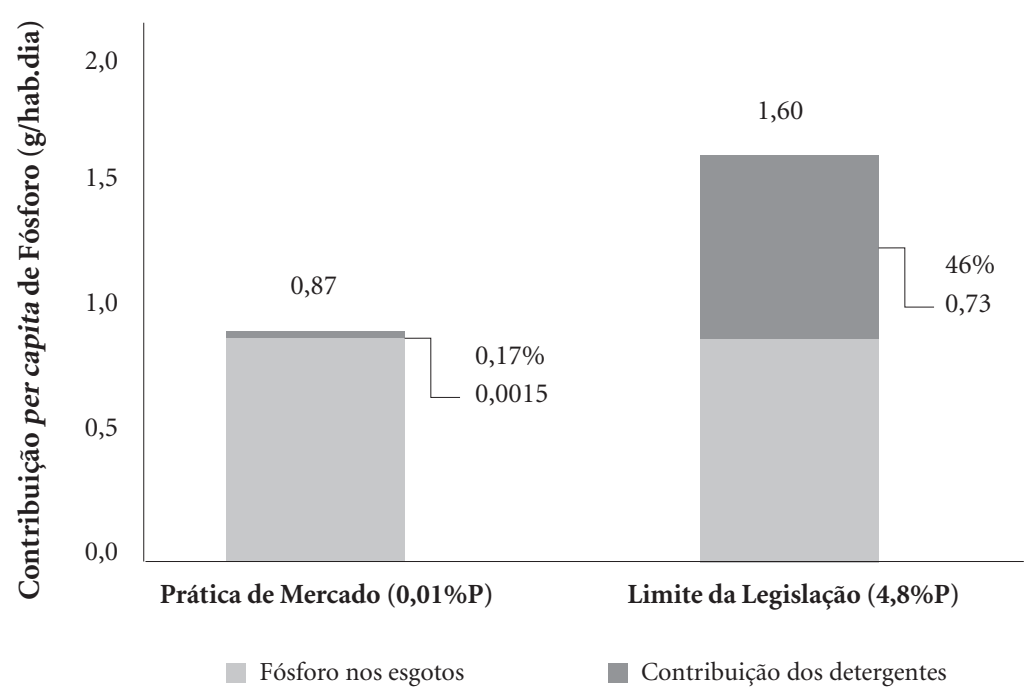

Gráfico 1. Fósforo nos esgotos: comparativo entre a contribuição dos detergentes com base na atual prática de mercado e no limite estipulado pela legislação. 
águas, caso o setor de fabricação de produtos de limpeza passe a cumprir o limite em vigor.

Além da redução da disponibilidade hídrica pelo aumento dos episódios de eutrofização, tal cenário poderá implicar numa ampliação do risco de ocorrência de blooms de cianofíceas, tornando inviável o uso de importantes mananciais para abastecimento da população, o que certamente trará reflexos à saúde pública.

\section{Discussão}

A relação entre aporte de fósforo e deterioração dos recursos hídricos é um assunto que tem merecido crescente atenção no decorrer das últimas décadas. Na Europa, por exemplo, esse tema vem sendo debatido desde meados da década de 1950, quando as medidas para controle das fontes do nutriente passaram a ser implementadas, conforme as diversidades na capacidade de investimento de cada país. No âmbito da Comunidade Europeia, visando dar uma tratativa unificada para o assunto, foram estipuladas em 1991, as atuais metas para melhorias graduais nos sistemas de coleta e tratamento dos esgotos, cuja evolução é alvo de constante acompanhamento e controle. Em 2000, esse tema passou a englobar a atividade agrícola e demais impactos difusos sobre os recursos hídricos, e em 2013, foi estabelecido um limite linear para fósforo nos detergentes para roupas comercializados nos Estados-Mem$\operatorname{bros}^{2,10}$. A despeito dos investimentos efetuados, e da considerável redução das cargas de fósforo e outros poluentes, o Oitavo Relatório de acompanhamento, publicado em 04/03/16, aponta a existência, ainda, de "lacunas significativas em matéria de conformidade"20.

Nos Estados Unidos e Canadá, os esforços direcionados para controle das fontes pontuais e difusas de nutrientes na região dos Grandes Lagos, iniciados ainda na década de 1960, incluíram a restrição do uso de detergentes fosfatados em diversas localidades e resultaram em significativa evolução da qualidade das águas. No entanto, no relatório anual publicado em 2016, o IJC ${ }^{21}$ indicou a necessidade de aprimorar as políticas de regulação e fiscalização das fontes, já que diversos mananciais ainda enfrentavam problemas decorrentes da eutrofização. Ao longo de 2015, representantes da entidade percorreram eventos públicos para informar a população a respeito da qualidade das águas, fornecer material didático e disseminar conceitos relativos ao controle da eutrofização. Concomitantemente, efetuou-se a divulgação continuada on-line dos dados de monitoramento, abrindo um espaço coletivo para discussão em blog, bem como, criando canais para partilha de informação em plataformas de mídia social.

Diante de todo o exposto, quanto ao Brasil, alguns pontos merecem ser trazidos ao debate. Os dados aqui apresentados, indicam que os produtos destinados à limpeza de tecidos atualmente comercializados no Brasil possuem uma reduzida concentração de fósforo. Face ao aporte total de fósforo nas águas, a contribuição dos detergentes em pó pode ser considerada, hoje, muito pouco representativa, podendo-se inferir que a sua atual participação para a ocorrência da eutrofização no país seja praticamente nula. Tais resultados apontam para uma importante evolução, pois a restrição à presença de fósforo em um produto largamente consumido pela população, é considerada uma ação preventiva aos processos de poluição, resultando em ganhos efetivos para a qualidade das águas e a saúde pública.

Constata-se, portanto, que a indústria nacional de detergentes seguiu os avanços implementados em outros países, e optou por substituir o STPP na formulação dos detergentes. Alinhou-se também, às conclusões elaboradas pelo Conama no ano de $2010^{15}$, conforme anteriormente abordado, que indicou a necessidade de propor limites mais restritivos para fósforo na formulação dos detergentes em pó.

Essa conduta, no entanto, carece de regulamentação. Em um trabalho de revisão das ações adotadas na Nova Zelândia, Reino Unido e Estados Unidos para a gestão do aporte de fósforo nas águas, McDowell et al. ${ }^{22}$ relatam que os instrumentos mandatórios foram fundamentais para estimular o cumprimento de medidas discutidas e implementadas de maneira voluntária, e assim, sujeitas à volatilidade do mercado. Necessita-se, portanto, evoluir com o conteúdo dos dispositivos legais existentes no país, por meio da redução dos limites dispostos pela Resolução Conama no 359/05. Tal medida permitirá que as condições praticadas pelo setor produtivo, e já incorporadas pelo mercado, sejam inseridas no âmbito da política pública, promovendo a manutenção do controle dessa importante fonte de fósforo no meio ambiente.

Outro ponto a ser observado é a lacuna existente no nível de informação da população sobre a importância da regulação dos detergentes fosfatados para a melhoria da qualidade das águas. Necessita-se definir e implementar uma estratégia para divulgação do assunto junto aos consu- 
midores, instituindo um processo de comunicação claro, que contribua para o alicerçamento de novos paradigmas de produção e consumo, e para o aprimoramento das ferramentas de educação e conscientização ambiental.

Ainda que a regulamentação legal seja primordial para promover a adequação técnica dos detergentes e dos processos produtivos, os trabalhos de informação e comunicação da população, como a rotulagem de produtos ambientalmente adequados, são dispositivos indispensáveis para estímulo ao controle social, por meio das quais pode-se obter a perenidade das ações e a evolução das condições ambientais a médio e longo prazos.

A integração da informação às dimensões de análise e ação na relação entre saúde e ambiente, oferece suporte à transformação das bases econômica, política, cultural e técnico-científica, resultando na compreensão da realidade social, na identificação de formas concretas para atuar conscientemente frente aos problemas ambientais e no fomento de práticas sustentáveis ${ }^{9}$.

Conforme citam Piccoli et al. ${ }^{23}$, por meio das práticas de comunicação e educação ambiental, as pessoas podem ter sua percepção ampliada, fortalecendo a sensação de pertencimento com relação aos assuntos de natureza ambiental, em especial com relação à gestão das águas.

Desta forma, ainda que ocorra uma mudança no contexto mercadológico, no sentido de que o fosfato passe a apresentar maior vantagem econômica para o setor produtivo de detergentes em pó, os mecanismos regulatórios e a educação ambiental poderão contribuir para que essa importante fonte de fósforo para o meio ambiente permaneça sob controle.

\section{Considerações finais}

Os dados apresentados neste trabalho indicam uma importante evolução, na medida em que aponta uma mudança de paradigma no setor produtivo de detergentes em pó, com a introdução no mercado brasileiro dos produtos com baixo teor de fosfato. Tal mudança segue em consonância com as ações já implementadas em outras localidades do mundo.

Observa-se, no entanto, um descompasso entre a prática e o ambiente normativo, uma vez que a legislação que regulamenta o assunto no Brasil estabelece limites sensivelmente superiores aos valores que vêm sendo adotados pelas indústrias. Discrepante também encontra-se o nível de informação da população a respeito do assunto, visto que as alterações implementadas, que ao que se pode perceber, ocorreram de forma unilateral, não foram revestidas de um processo de conscientização e comunicação a respeito dos benefícios ao meio ambiente e à saúde pública.

A regulamentação da presença de fósforo nos detergentes em pó é notoriamente reconhecida como uma medida preventiva aos processos de poluição das águas e, como tal, não pode ser relegada a um segundo plano. Por meio de mecanismos de regulação e educação ambiental será possível contribuir para a manutenção do controle dessa importante fonte de fósforo para o meio ambiente, auxiliando na garantia dos aspectos quantitativos e qualitativos da água, com reflexos diretos nas condições de saúde pública da população. Não obstante, a efetividade e a perenidade das mudanças ora em prática no Brasil dependem de uma evolução também no âmbito das políticas públicas.

\section{Colaboradores}

CMG Quevedo e WS Paganini participaram conjuntamente das etapas de concepção, análise e interpretação de dados, redação e revisão do artigo, bem como, da aprovação da versão final a ser publicada. 


\section{Referências}

1. International Joint Commission (IJC). Pollution of lake Erie, lake Ontario and the international section of St. Lawrence river. International Lake Erie Water Pollution Board and the International Lake Ontario - St Lawrence River Water Pollution Board. Ontario: IJC; 1969.

2. Glennie EB, Littlejohn C, Gendebien A, Hayes A, Palfrey R, Sivil D, Wright K. Phosphates and alternative detergent builders: final report. Wiltshire: EU Environment Directorate; 2002.

3. Hauthal HG. Types and typical ingredients of detergents. In: Waldhoff H, Spilker R, organizadores. Handbook of detergents. New York: Marcel Dekker Inc.; 2005. p. 1-100. (Part C: analysis. Surfactant Science Series).

4. Hartig JH, Zarull MA, Ciborowski JJH, Gannon JE, Wilke E, Norwood G, Vincent A. State of strait: status and trends of key indicators. Great Lakes Institute for Environmental Research. Ontario: University of Windsor; 2007.

5. Lamparelli MC, Tucci A, Sant'Anna CL, Pires DA, Lerche LHM, Carvalho MC, Rosal C. Atlas de cianobactérias da bacia do Alto Tietê. São Paulo: CETESB; 2014.

6. Lamparelli MC. Graus de trofia em corpos d'água do estado de São Paulo [tese]. São Paulo: Universidade de São Paulo; 2004.

7. Cordell D, Rosemarin A, Schoroder JJ, Smit AL. Towards global phosphorus security: a systems framework for phosphorus recovery and reuse options. Chemosphere 2001; 84(6):47-58.

8. Xavier CF, Dias LN, Brunkow RF. Eutrofização. In: Andreoli CV, Carneiro C, organizadores. Gestão integrada de mananciais de abastecimento eutrofizados. Curitiba: Sanepar Finep; 2005. p. 271-299.

9. Sorrentino M, Trajber R, Mendonça P, Ferraro Junior LA. Educação ambiental como política pública. Rev. Educação e Pesquisa 2005; 31(2):285-299.

10. European Parliament (EUROPARL). Fish-friendly laundry and dishwasher detergents. European Parliament News [internet]. $2011 \mathrm{dec} 14$ [acessado 2016 Mar 05]. Disponível em: http://www.europarl.europa.eu/ news/en/news-room/20111213IPR34069/

11. Quevedo CMG. Avaliação da presença de fósforo nos esgotos sanitários e da atual contribuição dos detergentes [tese]. São Paulo: Universidade de São Paulo; 2015.

12. Associação Brasileira das Indústrias de Produtos de Limpeza e Afins (ABIPLA). Anuário ABIPLA 2012. São Paulo: ABIPLA; 2012.

13. Associação Brasileira das Indústrias de Produtos de Limpeza e Afins (ABIPLA). Anuário ABIPLA 2015. São Paulo: ABIPLA; 2015.

14. Quevedo CMG, Paganini WS. Detergents as a source of phosphorus in sewage: the current situation in Brazil. Water, Air, \& Soil Pollut 2016; 227(1):14.

15. Conselho Nacional do Meio Ambiente (Conama). Relatório final: grupo de monitoramento do fósforo. Resolução Conama 359/05. Relatório dos Trabalhos Desenvolvidos pelo Grupo Técnico Fósforo Total. Ministério do Meio Ambiente. Brasília: MMA; 2010.
16. Global Material Supply Management (GMSM). Resolução 359 do Conama. [internet]. [acessado $2014 \mathrm{Fev} 12$ ]. Disponível em: http://www.gmsm.com.br/higieneelimpeza

17. Silva FSVCB, Silva VL, Lavorante AF, Paim APS. Utilização de planejamento fatorial no preparo de amostras de detergente em pó para a determinação de fósforo por análise em fluxo. Rev. Quím. Nova 2010; 33(5):1199-1203.

18. Souza ACS, Cardoso CE, Fraguas Neto MR. Determinação da concentração de fosfato em amostras de detergente em pó utilizando detecção titulométrica. Rev. Eletrônica Teccen 2010; 3(4):19-28.

19. Trajano G. Detergente em pó: produto com maior poder de lavagem e menor consumo de água é o desafio do mercado. Portal Química e Derivados [internet]. $2011 \mathrm{dez}$ 15. [acessado 2016 Set 12]. Disponível em: http://www. quimica.com.br/detergente-em-po/

20. European Commission (EC). Eighth report on the implementation status and the programmes for implementation (as required by article 17) of Council Directive 91/271/EEC concerning urban wastewater treatment. Brussels: EC; 2016 Mar. [Report No.: SWD(2016) 45 final].

21. International Joint Commission (IJC). 2015 Annual activities report. Ontário: A/GIS/GPS; 2016.

22. McDowell RW, Dils RM, Collins AL, Flahive KA, Sharpley AN, Quinn J. A review of the policies and implementation of practices to decrease water quality impairment by phosphorus in New Zealand, the UK, and the US. Nutr. Cycl. Agroecosyst. 2016; 104(1):289-305.

23. Picolli AS, Kligerman DC, Cohen SC, Assumpção RF. A educação ambiental como estratégia de mobilização social para o enfrentamento da escassez de água. Cien Saude Colet 2016; 21(3):797-808.

Artigo apresentado em 02/06/2016

Aprovado em 25/11/2016

Versão final apresentada em 27/11/2016 